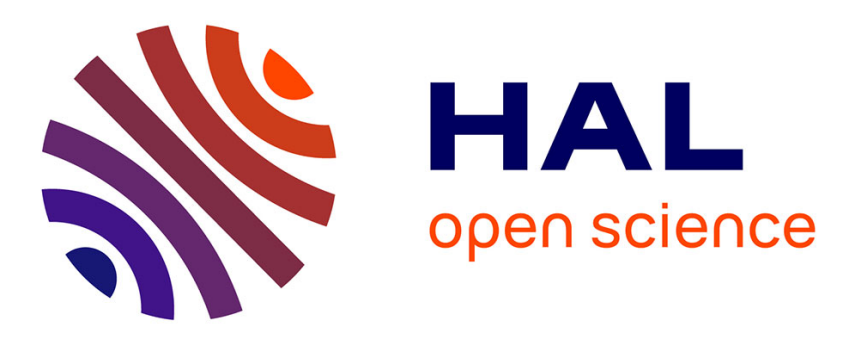

\title{
A comparison of methods for delineation of wave boundaries in 12 Lead ECG
}

Pauline Guyot, Pascal Voiriot, Stéphane Papelier, Levy Batista, Thierry

Bastogne

\section{- To cite this version:}

Pauline Guyot, Pascal Voiriot, Stéphane Papelier, Levy Batista, Thierry Bastogne. A comparison of methods for delineation of wave boundaries in 12 Lead ECG. Safety Pharmacology Society 2017 Annual Meeting, SPS 2017, Sep 2017, Berlin, Germany. hal-01669454

\section{HAL Id: hal-01669454 https://hal.science/hal-01669454}

Submitted on 20 Dec 2017

HAL is a multi-disciplinary open access archive for the deposit and dissemination of scientific research documents, whether they are published or not. The documents may come from teaching and research institutions in France or abroad, or from public or private research centers.
L'archive ouverte pluridisciplinaire HAL, est destinée au dépôt et à la diffusion de documents scientifiques de niveau recherche, publiés ou non, émanant des établissements d'enseignement et de recherche français ou étrangers, des laboratoires publics ou privés. 


\section{A comparison of methods for delineation of wave boundaries in 12 Lead ECG \\ Pauline Guyot ${ }^{1,3}$, Pascal Voiriot ${ }^{4}$, Stéphane Papelier ${ }^{4}$, Levy Batista1,3, Thierry Bastogne1,2,3 \\ 'CRAN, 2INRIA BIGS, ${ }^{3}$ CYBERnano, ${ }^{4}$ Banook CARDIABASE}

Objective: In the diagnosis of cardiac diseases, the delineation of electrocardiogram is crucial in order to efficiently classify cardiac events. Delineation consists in detecting the different peaks and boundaries of the QRS-complex, Pwave and T-wave. Several techniques have been proposed to face this issue. The objective is to assess the detection performances of a recent approach (non-negative matrix factorization) that has never been applied to ECG delineation and to compare its results with three known methods: morphological approach, discrete wavelet transform and difference operation method.

\section{Database}

The data are composed of 516 original 12 Lead ECGs of 10 seconds coming from Banook database. All signals have been reviewed and annotated by cardiologists. The dataset combines normal cardiac activity but also a variety of cardiac arrhythmia.

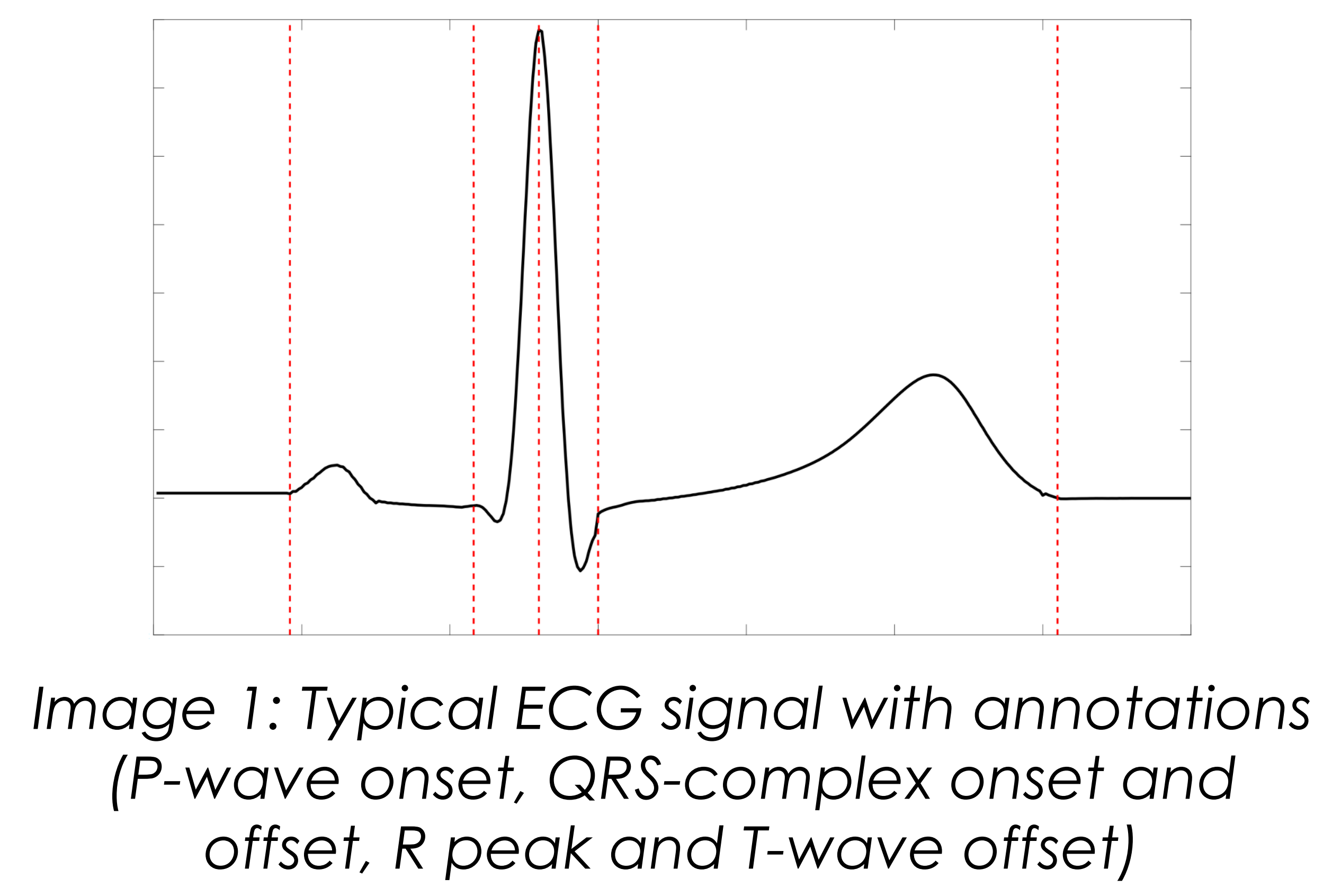

\section{Methods \& results}

The three known methods procede the same way:

(i) Mathematical transformation (with morphological computing, DWT transform or difference operation),

(ii) Dynamic or static thresolding for each waves

(iii) Check with a-priori information
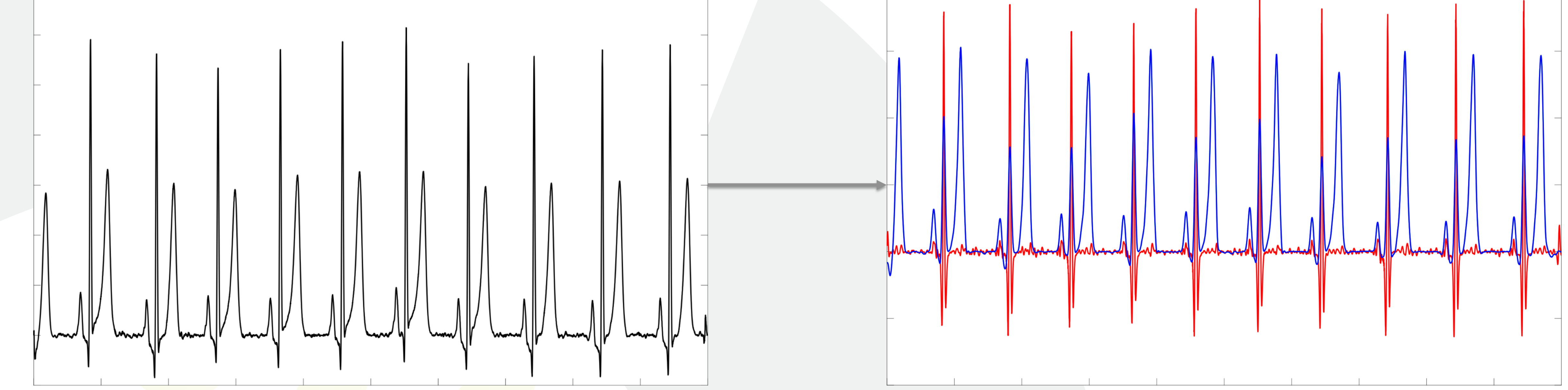

Image 2: ECG signal of 10 secondes (Lead I)

Image 3: NMF separation in two sources
Non-negative matrix factorization is a method of blind source separation (BSS) which allow to recover source signals from signal mixture without any information on the model. The only constraint is the non-negativity of the signals. In our case, we use the spectral information.
First source concentrates only Rpeaks whereas second source focuses on P and T-waves and a part of QRS complexes.

As the spectral density of QRS complexes and other waves overlap, it is normal not to exactly separate QRS and non-QRS parts.

\begin{tabular}{|c|c|c|c|c|c|c|c|c|}
\hline Methods & wave onset & T-wave offset & QRS onset & $R$ peak & QRS offset & Time of execution & QT interval & QRS interval \\
\hline $\begin{array}{c}\text { Morphological } \\
\text { approach }\end{array}$ & $082 \pm 6,178$ & 092 & 4,856 & 0,416 & $-0,0$ & 2 & & \\
\hline DWT approach & & & & & & & & 097 \\
\hline $\begin{array}{r}\text { Differenc } \\
\text { operation m }\end{array}$ & 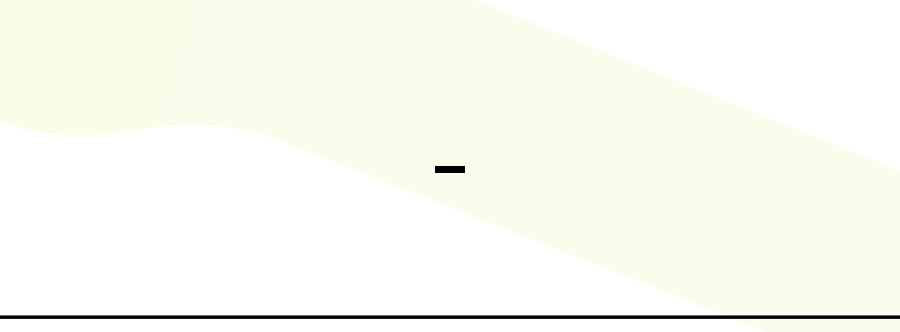 & - & $\longleftrightarrow 5$ & $0,636=$ & 0721 & 201 & - & ,462 \\
\hline NMF & $522 \pm 36,12$ & $0,298 \pm 29,06$ & 0,825 & 247 & 1,20 & 2,00 & $-0,527$ & 24,31 \\
\hline
\end{tabular}

Tab. 1: Error beween cardiologists annotations and algorithms' results (in milliseconds) and time of execution (in Matlab R2017a)

Main issues with NMF :

- Nonuniqueness property of NMF (reconstructed signals can vary signficantly)

- Time consuming

- Blind source separator (can separate R peaks from non-QRS parts but also noise from meaningful signal, necessity of a supervisor)

\section{Conclusion}

Delineation of $\mathbf{R}$-peaks is the easiest target to be accomplished, whereas the delineation of non-QRS parts (P-wave and T-wave fiducial points) is the most challenging issue for all methods. Improved techniques of NMF have to be investigated but first results show the feasibilty of this method. 